\title{
Journal of Neurocritical

\section{Feasibility, Safety, and Follow-up Angiographic Results of Endovascular Treatment for Non-Selected Ruptured Intracranial Aneurysms Under Local Anesthesia with Conscious Sedation}

\author{
Jongsoo Kang, MD' ${ }^{1}$, Chul-Hoo Kang, MD², Jieun Roh, MD², Jeong A Yeom, MD², Dong-Hyun Shim, $\mathrm{MD}^{3}$, Young Soo Kim, MD", \\ Sang Won Lee, MD, PhD ${ }^{5}$, Young-Soo Kim, MD ${ }^{1}$, Kee Hong Park, MD ${ }^{1}$, Chang-Hun Kim, MD ${ }^{1}$, Soo-Kyoung Kim, MD ${ }^{1}$, \\ Nack-Cheon Choi, MD, PhD ${ }^{1}$, Oh-Young Kwon, MD, PhD' ${ }^{1}$, Heeyoung Kang, MD, PhD' ${ }^{1}$, Seung Kug Baik, MD, PhD ${ }^{6}$ \\ ${ }^{1}$ Department of Neurology and Institute of Health Science, Gyeongsang National University College of Medicine, Jinju; '2Department of Radiology, Pusan National University \\ Yangsan Hospital, Pusan National University School of Medicine, Yangsan; ${ }^{3}$ Deaprment of Neurology, Samsung Changwon Hospital, Sungkyunkwan University School of \\ Medicine, Changwon; ${ }^{4}$ Department of Neurosurgery, MH Yeonse Hospital, Changwon; ${ }^{5}$ Department of Neurosurgery, Pusan National University Yangsan Hospital, Pusan \\ National University School of medicine, Yangsan; ${ }^{6}$ Department of Radiology, Research Institute for Convergence of Biomedical Science and Technology, Pusan National \\ University Yangsan Hospital, Pusan National University School of Medicine, Yangsan, Korea
}

Background: At most centers, general anesthesia (GA) has been preferred for endovascular treatment (EVT) of ruptured intracranial aneurysms (RIAs). In this study, we analyzed procedural results, clinical outcomes, and follow-up angiographic findings for patients undergoing EVT for RIA under local anesthesia (LA) with conscious sedation (CS).

Methods: We retrospectively evaluated 308 consecutive patients who underwent EVT for RIAs at a single institution between June 2009 and February 2017. EVT under LA with CS was considered for all patients with aneurysmal subarachnoid hemorrhage, regardless of Hunt and Hess $(\mathrm{HH})$ scale score.

Results: EVT was performed for 320 aneurysms in 308 patients with subarachnoid hemorrhages. The mean patient age was $55.5 \pm 12.6$ years. Moderate (III) and poor (IV, V) HH grades were observed in $75(24.4 \%)$ and 77 patients (25\%), respectively. Complete occlusion immediately after EVT was achieved for 270 (84.4\%) of 320 aneurysms. Thromboembolic complications and intraprocedural ruptures occurred in 25 (7.8\%) and 14 cases (4.3\%), respectively. The morbidity rate at discharge (as defined by a modified Rankin scale score of 3 or greater) was $27.3 \%$ (84/308), while the mortality rate was $11.7 \%$ (36/308). Followup angiographic results were available for 210 (68.1\%) of 308 patients. Recanalization was observed in 64 (29.3\%) of 218 aneurysms in 210 patients.

Conclusion: Based on our experience, EVT for RIAs under LA with CS was feasible, regardless of the clinical grade of the subarachnoid hemorrhage. Complication rates and follow-up angiographic results were also comparable to those observed when GA was used to perform the procedure

J Neurocrit Care 2018;11(2):93-101
Received October 11, 2018

Revised November 28, 2018

Accepted November 28, 2018

Corresponding Author:

Jongsoo Kang, MD

Department of Neurology and Institute of Health Science, Gyeongsang National University College of Medicine, 15 Jinjudaero 816beon-gil, Jinju 52727, Korea Tel: +82-55-750-8077

Fax: +82-55-755-1709

E-mail: rookies333@gmail.com

Copyright $\odot 2018$ The Korean Neurocritical Care Society

Key words: Intracranial aneurysms; Endovascular procedures; Anesthesia, Local

cc This is an Open Access article distributed under the terms of the Creative Commons Attribution Non-Commercial License (http://creativecommons.org/licenses/by$\mathrm{nc} / 4.0$ ) which permits unrestricted non-commercial use, distribution, and reproduction in any medium, provided the original work is properly cited. 


\section{INTRODUCTION}

Since the International Subarachnoid Aneurysm Trial demonstrated its safety and efficacy, endovascular treatment (EVT) involving coil embolization has been a mainstay of treatment for both unruptured and ruptured intracranial aneurysms. ${ }^{1}$ At most centers, coil embolization for ruptured intracranial aneurysm (RIA) is performed under general anesthesia (GA), which provides optimal conditions for the procedure. ${ }^{2}$ However, GA does not allow the evaluation of neurological status during the procedure, and several complications are associated with mechanical ventilation and anesthetics. ${ }^{3}$

At our institution, we performed EVT under local anesthesia (LA) with conscious sedation (CS) for all patients with RIA, regardless of the clinical severity of the subarachnoid hemorrhage (SAH). However, few studies have evaluated the procedural results of patients treated in this manner. ${ }^{4,5}$ Furthermore, the long-term follow-up angiographic results of RIAs treated by EVT under LA with CS have not been reported. Therefore, in the present study, we evaluated the procedural results, clinical outcomes, and long-term follow-up angiographic findings of patients undergoing EVT for RIAs under LA with CS.

\section{METHODS}

\section{Patients and data collection}

We retrospectively evaluated findings from 308 consecutive patients with aneurysmal SAHs who underwent EVT at a single institution between June 2009 and February 2017. This study was approved by the appropriate Institutional Review Board (IRB no. 05-2018-176), which waived the requirement for informed consent due to the retrospective nature of the study. Patients' demographics, initial neurological severity, length of hospital stay, clinical outcome at discharge, and mortality were extracted from each patient's electronic medical records. At the time of EVT for RIA, the following initial angiographic data were also collected: location and size of the treated aneurysms, height-to-neck ratio of the aneurysms, and immediate angiographic results following the procedure.

\section{Anesthetic technique}

EVT under LA with CS was considered for all patients with aneurysmal SAH, regardless of the Hunt and Hess $(\mathrm{HH})$ scale score. The groin was infiltrated with $5 \mathrm{~mL}$ of $1 \%$ lidocaine. A low dose of intravenous remifentanil (0.02-0.1 $\mu \mathrm{g} / \mathrm{kg} / \mathrm{min}$ ) was administered continuously for CS during the procedure. Ramsay sedation scale was used for assessment of the level of sedation. ${ }^{6}$ Light sedation of Ramsay sedation scale at 2 or 3 was used to avoid respiratory depression, snoring, and maintain patient cooperation for neurologic evaluation. An additional bolus of low-dose of propofol or midazolam was administered if the procedure could not be continued due to patient immobility and agitation. Patients who were expected to exhibit unstable respiration were intubated for airway protection prior to the procedure and additional mechanical ventilation was applied to patients with respiratory failure due to initial neurologic severity. However, an anesthesiologist did not attend the administration of anesthetics, and inhaled anesthetics and muscle relaxant were not used, except for the continuous infusion of low-dose remifentanil and an additional bolus of midazolam or propofol, when necessary. These procedures allowed for neurologic examination of patients undergoing mechanical ventilation. We defined the procedure as being performed under LA with CS, according to whether or not neurologic examination was possible, regardless of the application of mechanical ventilation. We continuously monitored patients' vital signs, including blood pressure, heart rate, respiratory rate, oxygen saturation, and electrocardiography.

\section{Endovascular procedure}

One neuroradiologist and one neurosurgeon performed each procedure. A radiolucent head-fixation device attached to the angiographic table was used to reinforce the immobility of the patient's head. A bolus of intravenous heparin $(50 \mathrm{IU} / \mathrm{kg})$ was injected immediately after placement of the guiding catheter. Under fluoroscopic guidance, 
aneurysms were treated in accord with standard procedures, using appropriate microcatheters, microwires, coils, and stents, as indicated.

\section{Angiographic follow-up}

First and second follow-up radiologic examinations were performed using conventional catheter angiography at 6 months and 1.5 years after the initial procedure. If the second examination showed no recanalization or no change of minor recanalization, a third follow-up angiography was performed using magnetic resonance angiography (MRA) one year after the second follow-up. If conventional angiography was not feasible, the exams were performed using MRA with three-dimensional reconstruction. The angiographic outcomes were determined based on RaymondRoy occlusion classification.?

\section{Statistical analysis}

Statistical analyses were performed with SPSS version 21.0 software for window (SPSS Inc., Chicago, IL, USA). Univariate analysis using Fisher's exact test, independent sample $t$-test, and Pearson's $\chi^{2}$ test were used, as appropriate. Multivariate logistic regression was performed to assess the independent contributions of $\mathrm{HH}$ grade to morbidity, mortality, and the degree of aneurysm obliteration. The results were considered significant for $P$ values $<0.05$.

\section{RESULTS}

\section{Characteristics of patients and aneurysms}

During the study period, a total of 308 consecutive patients harboring 399 aneurysms who had presented with aneurysmal SAH were treated via EVT. The study sample was composed of 123 men (39.9\%) and 185 women (60.1\%). The mean patient age was $55.5 \pm 12.6$ (standard deviation) years. A total of 104 patients (33.7\%) were age 61 or older. Eighty-eight patients (28.6\%) exhibited hypertension, while 45 (14.6\%) were smokers. Mild (I, II), moderate (III), and severe (IV, V) HH grades were noted in 156 (50.6\%), 75 (24.4\%), and 77 patients (25\%), respectively.
Sixty-six patients (21.4\%) had multiple aneurysms, and 12 patients were treated for two aneurysms at the same time. Of the 320 aneurysms treated, most lesions involved the anterior $(n=280,87.5 \%)$, rather than the posterior circulation $(n=40,12.5 \%)$. The aneurysms were located in the following vessels: internal carotid artery $(n=38,11.8 \%)$, posterior communicating artery ( $n=66,20.6 \%)$, middle cerebral artery $(n=54,16.8 \%)$, anterior communicating artery $(n=101,31.5 \%)$, anterior cerebral artery $(n=21,6.5 \%)$, and vertebrobasilar system $(n=40,12.5 \%)$. The mean aneurysm size was $6.2 \pm 3.5 \mathrm{~mm}$ and a total of 105 (32.8\%) large aneurysms (7 mm or greater) were observed. Mean heightto-neck ratio of the aneurysms was $2.2 \pm 0.9$. Table 1 shows the characteristics of patients and aneurysms.

\section{Procedural results, complications, and clinical outcomes}

The median door-to-puncture time was $2.73 \pm 0.33$ hours, while mean procedure time was $2.26 \pm 1.1$ hours. Simple coil embolization (CE), stent-assisted CE, balloon and stent-assisted CE were performed for 232 (72.5\%), 71 (22.2\%), and 17 aneurysms (5.3\%), respectively. Complete occlusion (Raymond-Roy classification I) immediately after EVT was achieved for 270 (84.4\%) of 320 aneurysms (Table 2). Procedure-related adverse events involving thromboembolic complications and intraprocedural ruptures occurred in 39 (12.1\%) cases, 25 (7.8\%) and 14 (4.3\%), respectively.

Among the 308 included patients, EVT was completed under our protocol of anesthesia for 307 patients, while the remaining patient had extreme agitation and required conversion to general anesthesia with muscle relaxant and inhaled anesthetics under the supervision of an anesthesiologist. Seventy-three patients (23.7\%) were intubated prior to the procedure and mechanical ventilation was applied for 34 patients (11.0\%). Two patients of $\mathrm{HH}$ grade 3 underwent tracheal intubation and mechanical ventilation due to respiratory depression related CS during the procedures; however, the procedures were completed successfully. The morbidity rate at discharge (as defined by a modified Rankin scale score of 3 or greater) was $27.3 \%$ (84/308), while the mortality rate was $11.7 \%$ (36/308). 


\section{Follow-up angiographic results}

Follow-up angiography results were available for 218 aneurysms of 210 (68.1\%) patients. Conventional catheter angiography was used for most of these patients (conven-

Table 1. Characteristics of patients and aneurysms

\begin{tabular}{|c|c|}
\hline Variable & Value \\
\hline \multicolumn{2}{|l|}{ Patient demographics } \\
\hline Age (years) & $55.5 \pm 12.6$ \\
\hline$>60$ & $104(33.7)$ \\
\hline Sex, male & $123(39.9)$ \\
\hline Hypertension & $88(28.6)$ \\
\hline Smoking & $45(14.6)$ \\
\hline \multicolumn{2}{|l|}{ Hunt and Hess grade on admission } \\
\hline Grade 1 & $5(1.6)$ \\
\hline Grade 2 & $151(49)$ \\
\hline Grade 3 & $75(24.4)$ \\
\hline Grade 4 & $48(15.6)$ \\
\hline Grade 5 & $29(9.4)$ \\
\hline \multicolumn{2}{|l|}{ Modified Fisher grade } \\
\hline Grade 0 & $3(1.0)$ \\
\hline Grade 1 & $90(29.2)$ \\
\hline Grade 2 & $33(10.7)$ \\
\hline Grade 3 & $93(30.2)$ \\
\hline Grade 4 & 89 (28.9) \\
\hline Location of the treated aneurysm & 320 \\
\hline Internal carotid artery & $38(11.8)$ \\
\hline Posterior communicating artery & $66(20.6)$ \\
\hline Middle cerebral artery & $54(16.8)$ \\
\hline Anterior communicating artery & $101(31.5)$ \\
\hline Anterior cerebral artery & $21(6.5)$ \\
\hline Vertebrobasilar artery & $40(12.5)$ \\
\hline \multicolumn{2}{|l|}{ Aneurysm size } \\
\hline Maximal diameter (mm) & $6.2 \pm 3.5$ \\
\hline Diameter $\geq 7$ mm & $105(32.8)$ \\
\hline \multicolumn{2}{|l|}{ Multiplicity of aneurysm } \\
\hline 1 & $242(78.5)$ \\
\hline 2 & $44(14.3)$ \\
\hline 3 & $17(5.5)$ \\
\hline 4 & $4(1.3)$ \\
\hline 5 & $1(0.3)$ \\
\hline Height-to-neck ratio (mm) & $2.2 \pm 0.9$ \\
\hline
\end{tabular}

Values are presented as number (\%) or mean \pm standard deviation. tional angiography: $n=204,97.1 \%$; MRA only: $n=6,2.9 \%$ ). The mean time to last angiographic follow-up was 18.4 months. Recanalization was observed in $64(29.3 \%)$ of 218 aneurysms in 210 patients (Table 3). Twenty-eight of these aneurysms were retreated due to major recanalization. Adequate occlusion immediately after retreatment was achieved for 27 of 28 aneurysms.

Table 2. Results of initial procedure

\begin{tabular}{lc}
\hline Variable & Value \\
\hline Door-to-puncture time (hours) & $2.73 \pm 0.33$ \\
Procedural time (hours) & $2.26 \pm 1.1$ \\
Coiling techniques & \\
Simple coiling & $232(72.5)$ \\
Stent assisted coiling & $71(22.2)$ \\
Balloon and stent assisted coiling & $17(5.3)$ \\
Obliteration (RR) & \\
Class I & $270(84.4)$ \\
Class II & $45(14.1)$ \\
Class III & $5(1.5)$ \\
Procedural complication & \\
Thromboembolic events & $25(7.8)$ \\
Intraprocedural rupture & $14(4.3)$ \\
\hline
\end{tabular}

RR, Raymond-Roy classification.

Values are presented as number (\%) or mean \pm standard deviation.

Table 3. Clinical outcomes on discharge and follow-up angiographic results

\begin{tabular}{lc}
\hline Variable & Value \\
\hline Clinical outcome on discharge & 308 \\
Morbidity (mRS $\geq 3)$ & $84(27.3)$ \\
Mortality & $36(11.7)$ \\
Follow-up angiography & $\mathrm{n}=210$ \\
Modality & \\
Conventional angiography & $204(97.1)$ \\
MRA & $6(2.9)$ \\
Recanalization & $64(29.3)$ \\
Obliteration of follow-up angiography (RR) & 218 \\
Class I & $136(62.3)$ \\
Class II & $64(29.3)$ \\
Class III & $18(8.2)$ \\
\hline
\end{tabular}

mRS, modified Rankin scale; MRA, magnetic resonance angiography; RR, Raymond-Roy classification.

Values are presented as number (\%). 


\section{Results according to $\mathrm{HH}$ grades}

Good grade SAH group and poor grade SAH group were defined by $\mathrm{HH}$ grades 1 to 3 and 4 to 5, respectively. Clinical outcomes and procedural results between the good grade SAH group and the poor grade SAH group were compared (Table 4). The rates of tracheal intubation and application of mechanical ventilation were significantly higher in the poor grade SAH group than in the good grade SAH group (intubation rate: $72.7 \%$ versus $7.3 \%$, odds ratio [OR] 34.0, 95\% confidence interval $[\mathrm{Cl}] 16.3-70.3, P<0.001$; rate of application of mechanical ventilation: $35.1 \%$ versus $3.0 \%, O R 16.0,95 \% \mathrm{Cl} 6.6-39.2, P<0.001)$. The mean size of aneurysms was significantly larger in the poor grade SAH group than in the good grade SAH group $(7.16 \pm 4.31$ $\mathrm{mm}$ versus $5.98 \pm 3.29 \mathrm{~mm}, P=0.016$ ). The rates of morbidity and mortality were also significantly higher in the poor grade $\mathrm{SAH}$ group than in the good grade $\mathrm{SAH}$ group (morbidity: $53.2 \%$ versus $18.6 \%, P<0.001$; mortality: $32.5 \%$ versus $4.8 \%, P<0.001)$. However, there was no significant differences in procedural complications, obliteration degree of aneurysms after initial procedure, or recanalization rate of follow-up angiography between the two groups.

\section{DISCUSSION}

In most centers, EVT for RIAs has been preferred under $\mathrm{GA}$, which allows for airway protection, the maintenance of patient immobility for high image quality, and prevents sudden unexpected complications related to patient motion during the procedure. ${ }^{2}$ However, LA allows for neurological evaluation during the procedure, shortens the procedure room time, and reduces complications that occur under general anesthesia and mechanical ventilation, such as cardiopulmonary morbidity and mortality. ${ }^{3,8,9}$ In a systematic review and meta-analysis of 1,956 patients treated

Table 4. Comparison between good grade SAH group and poor grade SAH group

\begin{tabular}{|c|c|c|c|}
\hline & $\begin{array}{l}\text { Good grade SAH group } \\
(n=231)\end{array}$ & $\begin{array}{l}\text { Poor grade SAH group } \\
(n=77)\end{array}$ & $P$ value \\
\hline Age (years) & $55.1 \pm 12.8$ & $56.8 \pm 12.1$ & 0.324 \\
\hline Male & $89(38.5)$ & $34(44.2)$ & 0.421 \\
\hline Hypertension & $62(26.8)$ & $26(33.8)$ & 0.243 \\
\hline Aneurysms treated & 241 & 79 & \\
\hline Anterior circulation & $211(87.6)$ & 69 (87.3) & 1.000 \\
\hline Size $(\mathrm{mm})$ & $5.98 \pm 3.29$ & $7.16 \pm 4.31$ & 0.016 \\
\hline Intubation & $17(7.3)$ & $56(72.7)$ & $<0.01$ \\
\hline Mechanical ventilation & $7(3.0)$ & $27(35.1)$ & $<0.01$ \\
\hline Morbidity & $43(18.6)$ & $41(53.2)$ & $<0.01 *$ \\
\hline Mortality & $11(4.8)$ & $25(32.5)$ & $<0.01 *$ \\
\hline Door to puncture time (hours) & $2.8(0.57-31)$ & $2.7(1.5-71.8)$ & 0.883 \\
\hline Procedure time (hours) & $2.4 \pm 1.1$ & $2.1 \pm 1.2$ & 0.054 \\
\hline Thromboembolic events & $20(8.6)$ & $5(6.5)$ & 0.637 \\
\hline Intraprocedural rupture & $13(5.3)$ & $1(1.3)$ & 0.202 \\
\hline Obliteration after initial procedure (RR) & & & $0.123 *$ \\
\hline Class I & $205(85.1)$ & $66(83.5)$ & \\
\hline Class II & $35(14.5)$ & $9(11.4)$ & \\
\hline Class III & $1(0.4)$ & $4(5.1)$ & \\
\hline Recanalization on follow-up angiography & $55(29.1)$ & $9(31.9)$ & 0.829 \\
\hline
\end{tabular}

$\mathrm{SAH}$, subarachnoid hemorrhage; RR, Raymond-Roy classification.

Values are presented as number (\%), mean \pm standard deviation, or median (range).

*Multivariate logistic regression was performed for analysis. 
with LA or GA anesthesia types, Brinjikji et al. ${ }^{8}$ reported that patients receiving general anesthesia had higher odds of mortality (OR 2.59, 95\% Cl 1.87-3.58, $P<0.01)$, and respiratory complications (OR 2.09, 95\% Cl 1.36-3.23, $P<0.01)$. Several studies have demonstrated that placement of a flow diverter and EVT for unruptured intracranial aneurysms can be performed safely under LA. ${ }^{10,11}$ Ogilvy et al. ${ }^{11}$ reported a high rate of successful procedure completion (74.6\%) and low rates of overall procedure-related morbidity (1.2\%) and mortality (0.6\%), for a total of 496 unruptured aneurysms treated by LA with CS. In this study, even for non-selected RIAs, although mechanical ventilation was applied to 34 patients (11.0\%), procedures were completed for most (307) of the 308 patients under CS, demonstrating the feasibility of EVT under LA with CS. Furthermore, to the best of our knowledge, this is the first large-scale study to present the long-term follow-up angiographic results of non-selected RIAs treated by EVT under LA with CS.

EVT may lead to procedure-related complications. Thromboembolic complications and intraprocedural perforation for intracranial aneurysms, including unruptured aneurysms under GA have been reported to occur in 11$12.5 \%$ and $2.5-5 \%$ of cases, respectively. ${ }^{12-15} \mathrm{~A}$ previous study reported the rates of thromboembolic complications $(7.7 \%)$ and intraprocedural rupture (3.8\%) among patients with good grade SAH receiving CS. ${ }^{4}$ Park et al. ${ }^{5}$ reported a high rate of successful completion (98.4\%) of RIAs treated by EVT under LA, but the intraoperative rupture rate (12.9\%) was significantly higher for LA than GA, although thromboembolic rates (12.4\%) were similar. This study showed a complication rate of $12.1 \%$ among patients with non-selected RIA, which included rates of thromboembolic events and intraprocedural perforation of $7.8 \%$ and $4.3 \%$, respectively. There were also no significant differences in procedural complications, obliteration degree of aneurysms after the initial procedure, and recanalization rate seen at follow-up angiography between the good grade $\mathrm{SAH}$ group and the poor grade SAH group. However, the rates of tracheal intubation and application of mechanical ventilation were significantly higher in the poor grade
SAH group than in the good grade SAH group. Therefore, airway protection may be required for patients with poor grade $\mathrm{SAH}$, even if the procedures are performed under $L A$ with CS.

A major concern associated with EVT for RIA is the risk of recanalization of a coiled aneurysm, which potentially re-bleeds. Previous studies have reported various rates of recanalization following EVT for intracranial aneurysms, including unruptured aneurysms under GA, ranging from $7.7 \%$ to $52.2 \%{ }^{16-18}$ Several studies have reported that RIA is a risk factor for the recanalization of coiled aneurysms. ${ }^{17,18}$ In this study, despite follow-up angiographic data collected primarily through conventional catheter angiography, the recanalization rate was $29.3 \%$.

Re-bleeding is known to occur more frequently in the earlier phase after $\mathrm{SAH}$, with the highest frequency occurring within the first 24 hours (15\%), especially within the first 3-6 hours. ${ }^{19,20}$ Previous studies advocated for treatment of aneurysms as early as possible after SAH because the risk of poor outcome increased as time-to-treatment after SAH increased. ${ }^{21-24}$ In our study, EVT was initiated at a median of 2.73 hours after patients had arrived at the emergency room, and the mean procedure time was 2.26 hours. Early EVT was possible because there was no time required to prepare for $\mathrm{GA}$, and it also shortened the total room time for the procedure.

Thus, our outcomes were comparable to the results of the above series performed under GA, as well as other studies under LA. Table 5 shows the summary of literature reports on EVT for RIA under GA.

Remifentanil is an ultra-short acting opioid which is quickly metabolized and does not accumulate in the tissue. ${ }^{25}$ Continuous infusion of remifentanil with predictable pharmacokinetics has been used to achieve CS during various surgical procedures. ${ }^{26-28}$ However, its continuous infusion can also cause respiratory depression and inhibition of the sympathetic nervous system, resulting in decreased heart rate and blood pressure..$^{25} \mathrm{~A}$ previous report demonstrated a higher incidence of respiratory depression in the CS group receiving remifentanil at an infusion rate of 0.1 $\mu \mathrm{g} / \mathrm{kg} / \mathrm{min}$, compared to an infusion rate $0.05 \mu \mathrm{g} / \mathrm{kg} / \mathrm{min}^{28}$ 
Table 5. Summary of the literatures on EVT under GA for RIA

\begin{tabular}{|c|c|c|c|c|c|c|c|}
\hline Author & Study & $\mathrm{N}$ & TT & TE & IPR & $\mathrm{CO}$ & $\mathrm{RC}$ \\
\hline Raymond et al. $(2003)^{18}$ & $\mathrm{R}$ & 191 & NA & NA & NA & NA & $39.8 \%$ \\
\hline Park et al. $(2005)^{12}$ & $\mathrm{R}$ & 118 & NA & $11.0 \%$ & $7.6 \%$ & $62.7 \%$ & NA \\
\hline van Rooij et al. $(2006)^{29}$ & $\mathrm{R}$ & 681 & NA & $4.7 \%$ & $4.4 \%$ & NA & NA \\
\hline Bruening et al. $(2006)^{30}$ & $\mathrm{R}$ & 225 & NA & $7.1 \%$ & $4.3 \%$ & NA & NA \\
\hline Nguyen et al. $(2007)^{17}$ & $\mathrm{R}$ & 44 & NA & NA & NA & $41.9 \%$ & $52.2 \%$ \\
\hline Deng et al. $(2007)^{31}$ & $\mathrm{R}$ & 102 & NA & $5.8 \%$ & $8.8 \%$ & $61.8 \%$ & NA \\
\hline Bradac et al. $(2007)^{32}$ & $\mathrm{R}$ & 533 & $<2$ days & $6.6 \%$ & $3.9 \%$ & NA & NA \\
\hline Yu et al. $(2007)^{33}$ & $\mathrm{R}$ & 80 & $<3$ days & $2.5 \%$ & $0.0 \%$ & $83.8 \%$ & $7.7 \%$ \\
\hline Ries et al. $(2007)^{16}$ & $\mathrm{R}$ & $323 *$ & NA & NA & NA & $69.6 \%$ & $21.1 \%$ \\
\hline Nguyen et al. $(2008)^{34}$ & $\mathrm{R}$ & 682 & NA & NA & $3.1 \%$ & NA & NA \\
\hline Elijovich et al. $(2008)^{14}$ & $\mathrm{R}$ & 299 & NA & NA & $5.0 \%$ & NA & NA \\
\hline Fiehler et al. $(2008)^{35}$ & $P$ & 186 & NA & $10.8 \%$ & $4.5 \%$ & NA & NA \\
\hline Renowden et al. $(2009)^{36}$ & $\mathrm{R}$ & 711 & $<1$ day & $4.5 \%$ & $4.7 \%$ & NA & NA \\
\hline Linfante et al. $(2010)^{37}$ & $\mathrm{R}$ & 184 & NA & $10.3 \%$ & NA & NA & NA \\
\hline Pierot et al. $(2008)^{38}$ & $P$ & 782 & NA & $12.5 \%$ & NA & NA & NA \\
\hline Cho et al. $(2012)^{39}$ & $\mathrm{R}$ & 372 & NA & $10.5 \%$ & NA & NA & NA \\
\hline Kang et al. $(2014)^{40}$ & $\mathrm{R}$ & 322 & NA & NA & $4.8 \%$ & NA & NA \\
\hline Stapleton et al. $(2015)^{41}$ & $\mathrm{R}$ & 156 & NA & NA & $7.7 \%$ & NA & NA \\
\hline Spetzler et al. $(2015)^{42}$ & $P$ & 126 & NA & NA & NA & $57.9 \%$ & NA \\
\hline Fan et al. $(2017)^{43}$ & $\mathrm{R}$ & 231 & NA & $6.5 \%$ & $4.3 \%$ & NA & NA \\
\hline Nomura et al. $(2018)^{44}$ & $\mathrm{R}$ & 70 & NA & $7.1 \%$ & NA & NA & NA \\
\hline Present study & $\mathrm{R}$ & 308 & 2.73 hours & $7.8 \%$ & $4.3 \%$ & $84.4 \%$ & $29.3 \%$ \\
\hline
\end{tabular}

EVT, endovascular treatment; GA, general anesthesia; RIA, ruptured intracranial aneurysm; N, patient number; TT, timing of treatment; TE, thromboembolic events; IPR, intraprocedural rupture; CO, complete obliteration; RC, recanalization; R, retrospective study; NA, not assessed; P, prospective study.

*Number of patients including unruptured intracranial aneurysms.

In this study, EVT for $89 \%$ of patients was completed without mechanical ventilation. However, severe respiratory depression occurred in two cases of CS and required urgent intubation during the procedures. These results highlight the caution that must be employed using LA with CS.

This study has several limitations. This study was a retrospective study performed at a single institution. As such, our results are susceptible to selection bias and the effects of an incomplete dataset. Furthermore, adverse events were self-reported, and we did not compare outcomes between those treated under LA and those treated under GA. Although light sedation of the Ramsay sedation scale at 2 or 3 was desired for appropriate CS, there is a possibility that a considerable number of patients were overly- sedated by infusion of sedative drugs. LA may not be suitable for patients who are extremely restless and are deemed too risky to be treated under this type of anesthesia. Nevertheless, we experienced the feasibility of EVT under LA with CS for non-selected RIAs, and we hope that a future large prospective multicenter trial will verify our findings.

\section{CONCLUSION}

LA does not allow for high-quality radiographic imaging during EVT, and patients may experience discomfort and pain during the procedure. However, based on our experience, EVT for non-selected RIAs under LA with CS is feasible, and the rates of procedural complication and immediate, follow-up angiographic results were also compa- 
rable with those observed following the use of GA.

\section{REFERENCES}

1. Molyneux A, Kerr R, Stratton I, Sandercock P, Clarke M, Shrimpton I, et al. International Subarachnoid Aneurysm Trial (ISAT) of neurosurgical clipping versus endovascular coiling in 2143 patients with ruptured intracranial aneurysms: a randomised trial. Lancet 2002;360:1267-74.

2. Joung KW, Yang KH, Shin WJ, Song MH, Ham K, Jung SC, et al. Anesthetic consideration for neurointerventional procedures. Neurointervention 2014;9:72-7.

3. Davis MJ, Menon BK, Baghirzada LB, Campos-Herrera CR, Goyal M, Hill MD, et al. Anesthetic management and outcome in patients during endovascular therapy for acute stroke. Anesthesiology 2012;116:396-405.

4. Kan P, Jahshan S, Yashar P, Orion D, Webb S, Siddiqui AH, et al. Feasibility, safety, and periprocedural complications associated with endovascular treatment of selected ruptured aneurysms under conscious sedation and local anesthesia. Neurosurgery 2013;72:216-20.

5. Park SD, Kim JH, Chang CH, Jung YJ. Procedure-related complication rate for the endovascular treatment of aneurysmal subarachnoid hemorrhage under local anesthesia. / Cerebrovasc Endovasc Neurosurg 2016;18:215-22.

6. Ramsay MA, Savege TM, Simpson BR, Goodwin R. Controlled sedation with alphaxalone-alphadolone. $\mathrm{Br}$ Med I 1974;2:656-9

7. Roy D, Milot G, Raymond J. Endovascular treatment of unruptured aneurysms. Stroke 2001;32:1998-2004.

8. Brinjikji W, Murad MH, Rabinstein AA, Cloft HJ, Lanzino G, Kallmes DF. Conscious sedation versus general anesthesia during endovascular acute ischemic stroke treatment: a systematic review and meta-analysis. A/NR Am / Neuroradiol 2015;36:525-9.

9. Forrest IB, Rehder K, Cahalan MK, Goldsmith CH. Multicenter study of generalanesthesia. III. Predictors of severe perioperative adverse outcomes. Anesthesiology 1992;76:3-15.

10. Griessenauer CI, Shallwani H, Adeeb N, Gupta R, RangelCastilla $\mathrm{L}$, Siddiqui $\mathrm{AH}$, et al. Conscious sedation versus general anesthesia for the treatment of cerebral aneurysms with flow diversion: a matched cohort study. World Neurosurg 2017;102:1-5.

11. Ogilvy CS, Yang X, Jamil OA, Hauck EF, Hopkins LN, Siddiqui
$\mathrm{AH}$, et al. Neurointerventional procedures for unruptured intracranial aneurysms under procedural sedation and local anesthesia: a large-volume, single-center experience. / Neurosurg 2011;114:120-8.

12. Park HK, Horowitz M, Jungreis C, Genevro J, Koebbe C, Levy E, et al. Periprocedural morbidity and mortality associated with endovascular treatment of intracranial aneurysms. A/NR Am J Neuroradio/ 2005;26:506-14.

13. Pierot L, Cognard C, Anxionnat R, Ricolfi F, CLARITY Investigators. Ruptured intracranial aneurysms: factors affecting the rate and outcome of endovascular treatment complications in a series of 782 patients (CLARITY study). Radiology 2010;256:916-23.

14. Elijovich L, Higashida RT, Lawton MT, Duckwiler G, Giannotta S, Johnston SC, et al. Predictors and outcomes of intraprocedural rupture in patients treated for ruptured intracranial aneurysms: the CARAT study. Stroke 2008;39:1501-6.

15. Fiehler J, Byrne JV. Factors affecting outcome after endovascular treatment of intracranial aneurysms. Curr Opin Neurol 2009;22:103-8.

16. Ries T, Siemonsen S, Thomalla G, Grzyska U, Zeumer H, Fiehler J. Long-term follow-up of cerebral aneurysms after endovascular therapy prediction and outcome of retreatment. AJNR Am / Neuroradiol 2007;28:1755-61.

17. Nguyen TN, Hoh BL, Amin-Hanjani S, Pryor JC, Ogilvy CS. Comparison of ruptured vs unruptured aneurysms in recanalization after coil embolization. Surg Neurol 2007;68:19-23.

18. Raymond J, Guilbert F, Weill A, Georganos SA, Juravsky L, Lambert $A$, et al. Long-term angiographic recurrences after selective endovascular treatment of aneurysms with detachable coils. Stroke 2003;34:1398-403.

19. Javadpour M, Silver N. Subarachnoid haemorrhage (spontaneous aneurysmal). BMJ Clin Evid 2009;2009:1213.

20. Ohkuma H, Tsurutani H, Suzuki S. Incidence and significance of early aneurysmal rebleeding before neurosurgical or neurological management. Stroke 2001;32:1176-80.

21. Dorhout Mees SM, Molyneux A), Kerr RS, Algra A, Rinkel G). Timing of aneurysm treatment after subarachnoid hemorrhage: relationship with delayed cerebral ischemia and poor outcome. Stroke 2012;43:2126-9.

22. Whitfield PC, Kirkpatrick PJ. Timing of surgery for aneurysmal subarachnoidhaemorrhage. Cochrane Database Syst Rev 2001;(2):CD001697.

23. de Gans K, Nieuwkamp DJ, Rinkel G], Algra A. Timing of aneurysm surgery in subarachnoid hemorrhage: a systematic 
review of the literature. Neurosurgery 2002;50:336-40.

24. Baltsavias GS, Byrne JV, Halsey I, Coley SC, Sohn MJ, Molyneux AJ. Effects of timing of coil embolization after aneurysmal subarachnoid hemorrhage on procedural morbidity and outcomes. Neurosurgery 2000;47:1320-9; discussion 132931.

25. Bürkle H, Dunbar S, Van Aken H. Remifentanil: a novel, shortacting, mu-opioid. Anesth Analg 1996;83:646-51.

26. Goettel N, Bharadwaj S, Venkatraghavan L, Mehta J, Bernstein M, Manninen PH. Dexmedetomidine vs propofol-remifentanil conscious sedation for awake craniotomy: a prospective randomized controlled trial. Br / Anaesth 2016;116:81121.

27. Byun SH, Hwang DY, Hong SW, Kim SO. Target-controlled infusion of remifentanil for conscious sedation during spinal anesthesia. Korean / Anesthesiol 2011;61:195-200.

28. Cannata F, Spinoglio A, Di Marco P, Luzi M, Canneti A, Ricciuti $\mathrm{G}$, et al. Total intravenous anesthesia using remifentanil in extracorporeal shock wave lithotripsy (ESWL). Comparison of two dosages: a randomized clinical trial. Minerva Anestesiol 2014;80:58-65

29. van Rooij WJ, Sluzewski M, Beute GN, Nijssen PC. Procedural complications of coiling of ruptured intracranial aneurysms: incidence and risk factors in a consecutive series of $681 \mathrm{pa}-$ tients. A/NR Am / Neuroradiol 2006;27:1498-501.

30. Bruening R, Mueller-Schunk S, Morhard D, Seelos KC, Brueckmann H, Schmid-Elsaesser R, et al. Intraprocedural thrombus formation during coil placement in ruptured intracranial aneurysms: treatment with systemic application of the glycoprotein IIb/IIla Antagonist tirofiban. A/NR Am / Neuroradiol 2006;27:1326-31.

31. Deng J, Zhao Z, Gao G. Periprocedural complications associated with endovascular embolisation of intracranial ruptured aneurysms with matrix coils. Singapore Med / 2007;48:42933.

32. Bradac GB, Bergui M, Stura G, Fontanella M, Daniele D, Gozzoli L, et al. Periprocedural morbidity and mortality by endovascular treatment of cerebral aneurysms with GDC: a retrospective 12-year experience of a single center. Neurosurg Rev 2007;30:117-25.

33. Yu SC, Wong GK, Wong JK, Poon WS. Endovascular coiling versus neurosurgical clipping for ruptured intracranial aneurysms: significant benefits in clinical outcome and reduced consumption of hospital resources in Hong Kong Chinese patients. Hong Kong Med / 2007;13:271-8.

34. Nguyen TN, Raymond J, Guilbert F, Roy D, Bérubé MD, Mahmoud $\mathrm{M}$, et al. Association of endovascular therapy of very small ruptured aneurysms with higher rates of procedurerelated rupture. / Neurosurg 2008;108:1088-92.

35. Fiehler ), Boor S, Dörbecker R, Eckert B, Götz F, Hartmann M, et al. Table for optimization and monitoring of cerebral aneurysm therapy (TOMCAT). Clin Neuroradiol 2008;18:168-76.

36. Renowden SA, Benes V, Bradley M, Molyneux AJ. Detachable coil embolisation of ruptured intracranial aneurysms: a single center study, a decade experience. Clin Neurol Neurosurg 2009;111:179-88.

37. Linfante I, Etezadi V, Andreone V, DeLeo M, Alehashemi S, Shaw K, et al. Intra-arterial abciximab for the treatment of thrombus formation during coil embolization of intracranial aneurysms. / Neurointerv Surg 2010;2:135-8.

38. Pierot L, Spelle L, Vitry F, ATENA Investigators. Immediate clinical outcome of patients harboring unruptured intracranial aneurysms treated by endovascular approach: results of the ATENA study. Stroke 2008;39:2497-504.

39. Cho YD, Lee JY, Seo JH, Kang HS, Kim JE, Jung KH, et al. Intraarterial tirofiban infusion for thromboembolic complication during coil embolization of ruptured intracranial aneurysms. Eur J Radiol 2012;81:2833-8.

40. Kang DH, Goh DH, Baik SK, Park J, Kim YS. Morphological predictors of intraprocedural rupture during coil embolization of ruptured cerebral aneurysms: do small basal outpouchings carry higher risk? / Neurosurg 2014;121:605-12.

41. Stapleton CI, Walcott BP, Butler WE, Ogilvy CS. Neurological outcomes following intraprocedural rerupture during coil embolization of ruptured intracranial aneurysms. / Neurosurg 2015;122:128-35.

42. Spetzler RF, McDougall CG, Zabramski JM, Albuquerque FC, Hills NK, Russin J), et al. The barrow ruptured aneurysm trial: 6-year results. / Neurosurg 2015;123:609-17.

43. Fan L, Lin B, Xu T, Xia N, Shao X, Tan X, et al. Predicting intraprocedural rupture and thrombus formation during coiling of ruptured anterior communicating artery aneurysms. I Neurointerv Surg 2017;9:370-5.

44. Nomura M, Mori K, Tamase A, Kamide T, Seki S, lida Y, et al. Thromboembolic complications during endovascular treatment of ruptured cerebral aneurysms. Interv Neuroradiol 2018;24:29-39. 